\title{
Pathologies of Acute Interstitial Pneumonia in Feedlot Cattle
}

\author{
${ }^{1}$ Jose A. Valles, ${ }^{1}$ Michael D. Apley, \\ ${ }^{2}$ Chris D. Reinhardt, ${ }^{1}$ Steven J. Bartle and ${ }^{1}$ Daniel U. Thomson \\ ${ }^{I}$ Department of Diagnostic Medicine/Pathobiology, \\ College of Veterinary Medicine, Kansas State University, Manhattan, KS US \\ ${ }^{2}$ Department of Animal Science and Industry, \\ College of Agriculture, Kansas State University, Manhattan, KS US
}

Article history

Received: 5-5-2015

Revised: 9-07-2015

Accepted: 12-11-2015

Corresponding Auhtor:

Daniel U. Thomson

Department of Diagnostic

Medicine/Pathobiology,

College of Veterinary

Medicine, Kansas State

University, Manhattan, KS US

Email: dthomson@vet.ksu.edu

\begin{abstract}
Acute Interstitial Pneumonia (AIP) is a costly issue that affects feedlot cattle. Research has yet to elucidate the etiology of AIP; therefore a case-control study was conducted to evaluate possible management and physiological factors that contribute to AIP in feedlot cattle. The experiment was conducted during the summer of 2011 in a commercial feedyard in Kansas. Animals exhibiting clinical signs of AIP and a control animal from the same pen were selected for ante-mortem examination. Post-mortem AIP cases were also selected for additional examination. Ante-mortem measurements included rumen gas cap hydrogen sulfide and $\mathrm{pH}$, rectal temperature and body weight. Post-mortem examination added histological examination of lung tissue. Rectal temperature was greater in the AIP cattle $\left(40.6 \pm 0.16^{\circ} \mathrm{C}\right)$ than controls $\left(39.7 \pm 0.16^{\circ} \mathrm{C} ; \mathrm{p}<0.001\right)$. Body weight $(499 \pm 56$ Vs. $506 \pm 60 \mathrm{~kg})$, hydrogen sulfide (136 \pm 133 vs. $269.8 \pm 311$ ppm) and rumen $\mathrm{pH}(6.4 \pm 0.5$ Vs. $6.2 \pm 0.6)$ were similar between AIP and control cattle $(\mathrm{p}>0.10)$. Post-mortem rumen $\mathrm{pH}$ values were $6.3 \pm 0.4$ and $5.7 \pm 0.6$ for AIP and control cattle, respectively. Histological evaluation of lung samples showed that bronchiolitis was present in about $90 \%$ of the cattle affected with AIP. About $75 \%$ of the cattle with AIP also had bronchopneumonia. No relationships between feed intake patterns, or serum amylase or lipase levels were noted between treatments $(p>0.20)$. This study generally confirms that AIP tends to occur more in heifers relative to steers, occurs in cattle at heavier weights or later in the feeding period and tends to be associated pathologically with bronchio' litis and bronchopneumonia. The lack of differences in rumen measures and the feed intake data between AIP and control cattle suggest that feed intake patterns and rumen fermentation may not impact AIP in feedlot cattle and that it may be more directly related to bronchiolitis/bronchopneumonia due to chronic irritation or infection.
\end{abstract}

Keywords: Acute Interstitial Pneumonia, Feedlot Cattle, Lung Lesions

\section{Introduction}

Acute Interstitial Pneumonia (AIP) is a respiratory disease that affects feedlot cattle, especially during dry and hot weather patterns (Woolums et al., 2005a). This disease is also known as atypical interstitial pneumonia, fog fever and dust pneumonia (Woolums et al., 2005b). Following Bovine Respiratory Disease (BRD), AIP is one of the most costly diseases confronted by feedlots (Amosson et al., 2006). It tends to affect cattle that are near to their market weight and in addition to the loss of the animal, economic costs include the value of a large amount of feed, yardage, interest and any other investments in the animal (Loneragan et al., 2001b). In 2000, the National Animal Health Monitoring System reported that $78.4 \%$ of all feedlots had at least one animal develop AIP (NAHMS, 2000b). A survey of U.S. feedlot personnel estimated that $3.1 \%$ of the total cattle placed on feed develop AIP (NAHMS, 2000a).

Cattle affected by AIP develop clinical signs such as extension of the neck to facilitate breathing, excessive salivation, grunting, panting, breathing through the mouth and refusal to travel (Blood, 1962; Doster, 2010). Affected animals also may express 
aggressive attitudes when being approached for handling (Loneragan and Gould, 1999). Cattle that display AIP-like symptoms tend to respond poorly to treatments (Woolums et al., 2005b). At necropsy, lungs grossly display edema and emphysema (Doster, 2010). Even though it is a very costly disease, research has yet to elucidate the exact etiology of AIP in feedlot cattle. Factors such as heat stress, dust exposure, viruses, feed toxins, toxic gasses such as hydrogen sulfide produced in the rumen, gender, parasites and several other factors have been associated with AIP (Sorden et al., 2000; Doster, 2010). Feedlot veterinarians have speculated that pancreatitis may be involved with AIP. Hydrogen sulfide has been shown to cause lung lesions in rats (Lopez et al., 1987; Prior et al., 1988). Also in grazing cattle, AIP been tied to the L-tryptophan content of lush forages and the resulting 3-methylindole metabolism in the rumen (Loneragan et al., 2001a). This study was conducted to clinically observe ante-mortem cases of cattle suffering from AIP compared to their nonaffected pen cohorts and examine management conditions or cattle feeding behavior that might lead to AIP incidence in cattle feeding facilities. Also, an objective of this study was to assess the gross and histological pathology of cattle that died due to AIP to better understand the pathenogenesis of the disease.

\section{Materials and Methods}

\section{Cattle}

All procedures in the study were approved by the Institutional Animal Care and Use Committee at Kansas State University (No. 3044).

The study was conducted in a commercial feedlot with a capacity of approximately 55,000 head in southwest Kansas during the summer of 2011. The cattle population demographics consisted of $75 \%$ heifers and $50 \%$ black-hided animals. Average body weight at arrival of cattle was $354 \mathrm{~kg}$. At initiation of the study the cattle ranged from 3 to 166 Days On Feed (DOF) with an average of 64 DOF. The finishing diet was about $44 \%$ flaked corn, $20 \%$ high moisture corn, $22 \%$ wet distillers grains, $3.7 \%$ dry distillers grains, $5.1 \%$ ground corn stalks and $5.1 \%$ liquid supplement on a dry matter basis. Feed consumption data were obtained from the feedlot records.

Case animals suspected of AIP were identified antemortem based on clinical signs, which included: extension of the neck, panting, excessive salivation, breathing through the mouth and refusal to travel (Blood, 1962; Doster, 2010). Suspect animals were removed from their pen and taken to the hospital facilities for examination or were collected in the home pen if the animal was unable to rise. Animals diagnosed with AIP (case) were paired with a healthy control animal of comparable physical characteristics from the same pen. At the time of sample collection, the date, sex, lot and tag number and hide color were recorded. All sample collections were performed by a Kansas State University graduate student and properly trained personnel from the feedlot hospital crew.

\section{Samples}

In both case and control animals, samples from the rumen gas cap were collected using a rumen puncturing technique (Kleen et al., 2004). A total of $200 \mathrm{~mL}$ of rumen gas was collected for measurement of $\mathrm{H}_{2} \mathrm{~S}$ (100 $\mathrm{mL}$ per gas measured). Rumen hydrogen sulfide levels were determined using 2 detector tubes with different detection ranges (Gastec Corporation, Ayase-shi, Kanagawa, Japan). Hydrogen sulfide samples initially used a ${ }^{\mathrm{C} O} \mathrm{NO}$ H tube which had a range of 100 to 2,000 ppm. If the amount of $\mathrm{H}_{2} \mathrm{~S}$ exceeded the scale range, a second $100 \mathrm{~mL}$ sample was taken using a ${ }^{\mathrm{D}} \mathrm{NO} .4 \mathrm{HH}$ tube with a 0.1 to $2.0 \%$ scale range. Rumen fluid was obtained following a rumen sampling procedure similar to the technique used to collect the rumen gas samples. A 12-gauge needle was introduced into the rumen on the left side of the animal just caudal to the $13^{\text {th }}$ rib at the level of the point of the elbow. At least $6 \mathrm{~mL}$ of rumen fluid was obtained to measure the rumen $\mathrm{pH}$.

Blood samples were obtained for serum chemistry analysis. Approximately $12 \mathrm{~mL}$ of blood was obtained from the jugular vein and divided into 2 aliquots of $6 \mathrm{~mL}$ each, allowed to clot, centrifuged and refrigerated. The samples were then shipped for laboratory analysis of amylase and lipase contents (IDEXX Laboratories, Westbrook, Maine) to observe pancreatitis as a possible cause for acute lung injury as evidenced in human medicine (Zhou et al., 2010).

Rectal temperature was determined using an electronic digital thermometer. Body weight was recorded in the hospital chute for those animals receiving an ante-mortem examination. The weights for the animals receiving a postmortem examination but without an ante-mortem examination that died in their home pen were estimated using their home penmate's weight average.

Post-mortem examination was performed on suspected AIP mortalities independent of whether they had received an ante-mortem examination. Post-mortem case animals were confirmed based on lung histopathology. At the time of necropsy, post-mortem controls were selected from animals that were suspected of dying of causes other than AIP. Post-mortem AIP suspects and controls were paired by the best match of the animal's demographic information (sex, weight, home pen). Throughout the study, necropsies were performed by experienced personnel trained by the feedyard consulting veterinarian. Only animals suspected of AIP that died early in the morning and showed no signs of physical decomposition were examined.

Rumen gas-cap samples were obtained at necropsy following the same technique as the ante-mortem 
examination, except that the rumen was exposed. Rumen $\mathrm{pH}$ was collected by making a small incision in the rumen wall to insert the $\mathrm{pH}$ meter into the rumen liquor.

Lung tissue samples were obtained by a single trained person. Samples (4 total lung samples for each animal) were collected from lung lobes with consolidated tissue. In the majority of animals, the caudal lobe contained consolidated tissue and was the site of sample collection. Samples were collected along lines demarcation between consolidated and nonconsolidated tissue so that each sample contained both types of tissue. Tissues were sectioned in blocks of similar dimensions (approximately $6.35 \mathrm{~cm}$ length $\mathrm{x} 1.9$ $\mathrm{cm}$ width $\mathrm{x} 1.9 \mathrm{~cm}$ depth). Each sample was individually placed in formalin, labeled with the lot number, animal ID and lobe location. Formalin fixedsamples were stored in a room with no sunlight and at a temperature of approximately $21^{\circ} \mathrm{C}$. Samples were shipped on a weekly basis to the Arizona Veterinary Diagnostic Laboratory at the University of Arizona for histopathology analysis.

Post-mortem, animals were classified AIP positive by presenting histopathological lesions such as alveolar fibrin, hyaline membrane formation and pneumocyte hyperplasia in at least one lobe (Sorden et al., 2000; Woolums et al., 2004). Histopathological lesions were further defined as focal AIP (less than $10 \%$ of lobule affected), patchy AIP (more than $10 \%$ but less than $50 \%$ of the lobule affected), diffuse AIP (more than $50 \%$ of the lobule affected), bronchopneumonia (focal or diffuse acute/chronic), chronic bronchopneumonia (bronchopneumonia plus evidence of chronicity such as fibrosis or atelectasis), histopathological interstitial pneumonia (interstitial pneumonia lacking gross lesions described for AIP but having interstitial cellular or acellular interstitial infiltrates upon histopathological analysis). The presence of bronchopneumonia, bronchiolitis and interstitial pneumonia lesions were also evaluated.

Variation in 14-day feed consumption was compared in a case-control approach between pens with at least one case of AIP $(n=44)$ verses selected control pens with no reported cases of AIP. A second comparison in feed variation was made using a 5-day rolling average compared to the $6^{\text {th }}$ day feed consumption. The control pen was selected based on sex, DOF, average weight, number of cattle in the pen and location within the feedlot. For statistical analysis, dry matter intake variations were categorized as the number of pens varying from the previous day or the rolling average by $\geq 0.11,0.23$, or $0.34 \mathrm{~kg} \cdot$ animal $^{-1} \cdot$ day $^{-1}$.

Ambient temperature and humidity at the feedlot location were automatically recorded by a central station and a weather censor located on site. Samples collection was conducted from June 10 to August 10, 2011. High and low daily temperatures were graphed with the daily incidence of AIP in cattle.

\section{Statistical Analysis}

The experimental design was a case-control study to evaluate possible factors contributing to AIP in feedlot production settings. A $P$ value $\leq 0.05$ was selected to establish statistical significance among evaluations. Probability values $>0.05$ but $\leq 0.1$ were described as values approaching statistical significance. Ante-mortem observations of rectal temperature, weight, rumen $\mathrm{H}_{2} \mathrm{~S}$ and rumen $\mathrm{pH}$ were analyzed using a mixed-effects model analysis of variance (SAS Institute, Inc. Cary, NC) with ante-mortem classification as a fixed effect and with sex and pairing as random effects. Means were separated using the PDIFF option of SAS. This ante-mortem analysis focused on 23 pairs of AIP affected animals and controls.

Ante-mortem observations of serum amylase and lipase demonstrated biphasic distributions of zero and positive values and therefore, were evaluated using a Wilcoxon Ranked Sum procedure in SAS. The number of cattle in the various ante and post-mortem examination groups varied. Due to the large differences in numbers and the lack of histological confirmation of control animal lung pathology, serum amylase and lipase were reported but not statistically evaluated.

Feed consumption changes were analyzed using the Proc Mixed procedure to compare the pens with AIP cases to control pens without AIP cases. Pen classification, with or without an AIP case, was a fixed effect and no random effects were included in the model.

\section{Results}

The number of animals in the various ante-mortem and post-mortem groups are shown in Table 1. In this study, AIP affected cattle from 24 to 131 DOF and at an average body weight of $505 \mathrm{~kg}$.

\section{Ante-Mortem}

A total of 31 animals were diagnosed with AIP and received an ante-mortem examination. Serum chemistry was completed on 30 animals. Eighty-seven percent were heifers compared to the estimated heifer percentage in the feedlot of $75 \%$. Hide colors for the 31 animals were $74 \%$ black, $16 \%$ red and $10 \%$ white.

Twenty-three case controls were examined antemortem. Live weights were similar between the two groups $(499 \pm 56 \mathrm{Vs}$. $506 \pm 60 \mathrm{~kg})$. Sixteen of the 31 animals with ante-mortem examination also received a post-mortem examination.

The remaining 14 animals were in an advanced state of decomposition and necropsies were not performed. In addition, 44 possible AIP cases that died prior to the opportunity for an ante-mortem received post-mortem examination. Eleven post-mortem cattle that died from obviously non-AIP causes were selected as controls at the time of necropsy. A total of 71 cattle received postmortem examination. 
Table 1. Animal numbers in the various ante-mortem and post-mortem groups

\begin{tabular}{lllll} 
& Identified Ante-mortem & & Identified Post-mortem \\
Item & Ante-mortem examination & Post-mortem examination & Post-mortem examination & Lung examinations \\
\hline AIPa ${ }^{\mathrm{a}}$ suspect & 31 & 16 & 44 & 60 \\
Control & 23 & 0 & 11 & 0 \\
Lung histology & & 13 & 32 & 45 \\
AIP confirmed & 15 & 40 & 55 \\
Bronchiolitis & 10 & 24 & 34 \\
Bronchopneumonia & & & \\
acute interstitial pneumonia & & & \\
\hline
\end{tabular}

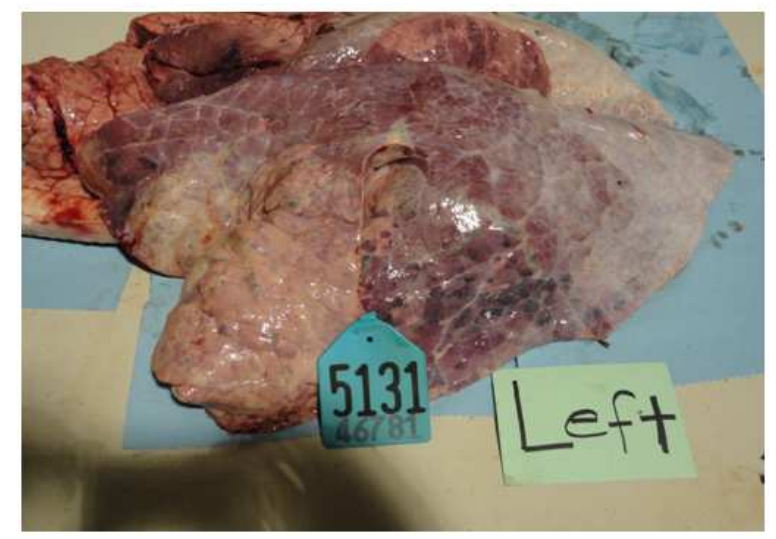

Fig. 1. Example of lung showing gross AIP lesions

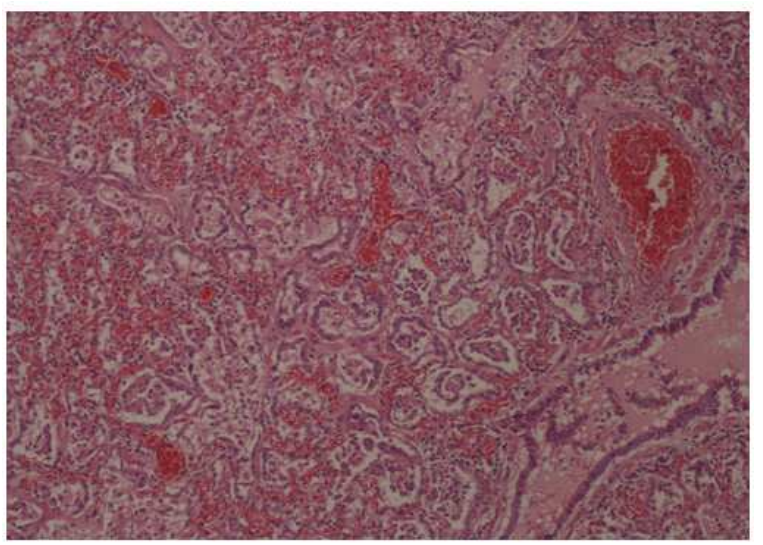

Fig. 2. Image of diffuse AIP lung lesions

In the ant-mortem examinations, there were no differences $(\mathrm{P}=0.99)$ in serum amylase or lipase concentrations, indicators of pancreas function, between control animals and AIP suspects (Table 2). Suspected AIP cases had numerically lower $(P=0.09)$ rumen gas cap hydrogen sulfide concentration $\left(\mathrm{H}_{2} \mathrm{~S} ; 110 \pm 68\right)$ than the control group (273 \pm 59 ; Table 2$)$. Rumen $\mathrm{pH}$ values among the control and the AIP suspect groups approached significance $(P=0.06$, Table 2$)$. Cattle suspected of AIP had greater $(p<0.0001)$ rectal temperature $\left(40.6 \pm 0.16^{\circ} \mathrm{C}\right)$ than the control animals $\left(39.7 \pm 0.16^{\circ} \mathrm{C}\right)$. There were no differences in body weights between the control cattle and the AIP suspect cattle $(P=0.22)$.

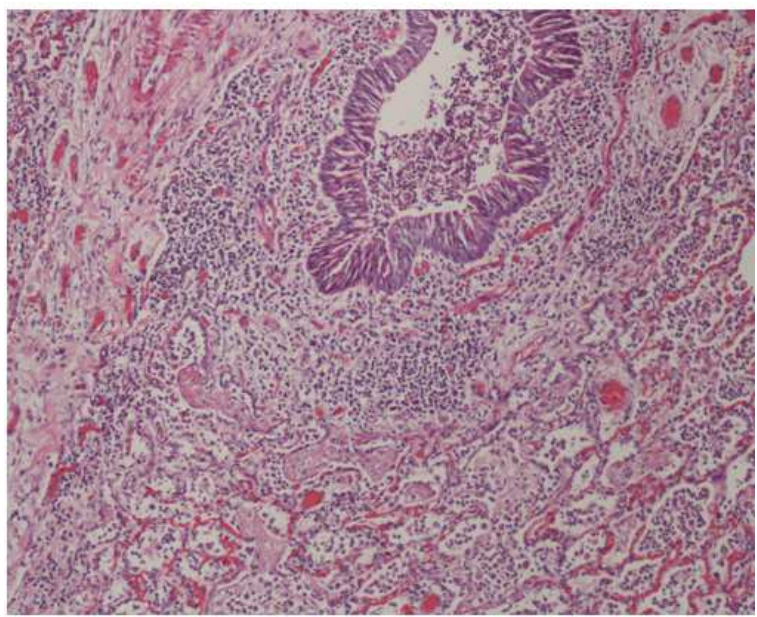

Fig. 3. Image of focal AIP lesions around bronchioles

\section{Post-Mortem}

Lung samples from 60 animals were submitted to the laboratory. Diffuse, focal and patchy AIP lesions were present in 45 of the 60 animals at levels that met the criteria for AIP diagnosis (Fig. 1). Single type lung lesions diagnosed 15 animals with $\operatorname{AIP}$ (5, 6 and 9 for diffuse (Fig. 2), focal (Fig. 3) and patchy, respectively) and 30 animals had more than one type of lesion present. In addition, AIP lesions were present in 10 animals but at less than $10 \%$ of lobule. Bronchopneumonia was confirmed to be present in 34 of the 60 animals. Fiftyfive of the 60 had lesions consistent with bronchiolitis.

In the post-mortem examinations, rumen $\mathrm{pH}$ values of the 60 AIP animals were numerically greater than the values obtained from 11 control animals, $6.3 \pm 0.4$ and $5.7 \pm 0.6$, respectively. Cattle with AIP also had numerically lower $\mathrm{H}_{2} \mathrm{~S}$ concentration $(1,280 \mathrm{ppm})$ than the control group $(1,841 \mathrm{ppm})$. Statistical significance between the AIP and control groups was not calculated for the rumen $\mathrm{pH}$ or hydrogen sulfide due to the lack of lung histology of the control group.

\section{Ante- and Post-Mortem}

Sixteen animals had both ante-mortem and postmortem examinations; 13 (81\%) had diffuse, focal and patchy AIP confirmed by histology. 
Table 2. Average ante-mortem rectal temperature, rumen hydrogen sulfide $\left(\mathrm{H}_{2} \mathrm{~S}\right)$, rumen $\mathrm{pH}$, and serum amylase and lipase for Control and cattle diagnosed with Acute Interstitial Pneumonia (AIP)

\begin{tabular}{lllllll}
\hline Treatment & $\mathrm{N}$ & Rectal temp., ${ }^{0} \mathrm{~F}$ & Rumen $\mathrm{H}_{2} \mathrm{~S}, \mathrm{ppm}$ & Rumen $\mathrm{pH}$ & Amylase, U/L & Lipase, U/L \\
\hline Control & 30 & 103.5 & 273 & 5.9 & 8.9 & 11.2 \\
AIP $^{\mathrm{a}}$ & 23 & 105.4 & 110 & 6.2 & 8.7 & 11.1 \\
SEM & & 0.30 & 68 & 0.3 & 2.4 & 5.8 \\
P value & $<0.001$ & 0.09 & 0.06 & 0.99 & 0.99 \\
\hline
\end{tabular}

${ }^{\mathrm{a}}$ Acute interstitial pneumonia

Table 3. Number of pens with changes in feed consumption volume during the 14 days prior to Acute Interstitial Pneumonia (AIP) incidence

\begin{tabular}{|c|c|c|c|c|}
\hline \multirow[b]{2}{*}{ Change kg $\cdot$ animal $^{-1} \cdot$ day $^{-1}$} & \multicolumn{2}{|c|}{ Number of pens } & \multirow[b]{2}{*}{ SEM } & \multirow[b]{2}{*}{$P$ value } \\
\hline & Control & AIP & & \\
\hline$>0.11$ & 8.3 & 7.7 & 0.3 & 0.03 \\
\hline$>0.23$ & 5.5 & 5.3 & 0.4 & 0.62 \\
\hline$>0.34$ & 3.7 & 3.6 & 0.3 & 0.88 \\
\hline
\end{tabular}

Table 4. Number of pens with changes in 5-day rolling average of feed consumption prior to Acute Interstitial Pneumonia (AIP) incidence

\begin{tabular}{|c|c|c|c|c|}
\hline \multirow[b]{2}{*}{ Change $\mathrm{kg} \cdot$ animal $^{-1} \cdot$ day $^{-1}$} & \multicolumn{4}{|c|}{ Number of pens } \\
\hline & Control & AIP & SEM & $P$ value \\
\hline$>0.11$ & 3.1 & 2.7 & 0.2 & 0.13 \\
\hline$>0.23$ & 2.0 & 1.8 & 0.2 & 0.59 \\
\hline$>0.34$ & 1.4 & 1.0 & 0.2 & 0.15 \\
\hline
\end{tabular}

Acute and chronic bronchiolitis lesions were found in 12 of the 13 animals with AIP and in the 3 animals with no histological AIP lesions. Of the 16 animals, 10 (63\%) had some form of bronchopneumonia.

\section{Weather and Feed Patternsi}

High and low daily temperatures were gathered from the weather station for a graphical analysis in comparison with the daily incidence of AIP in cattle. No association between temperature changes and the incidence of AIP was observed.

Comparisons of feed variations between the pens with at least one AIP incident during the time of the study and their assigned control pen were made. Feed variations were statistically evaluated between the AIP and control groups in $\geq 0.11,0.23$ and 0.34 $\mathrm{kg}$ /animal daily change. During both 14 (compared to the previous day) and 5 day (compared to the $5 \mathrm{~d}$ rolling average) periods prior to the AIP incidence, the number of pens with changes of $\geq 0.11,0.5$ and $0.34 \mathrm{~kg} \cdot$ animal-1-day-1 did not differ between pens with and without AIP cases ( $p=0.13$ to 0.88$)$. The results are shown in Tables 3 and 4.

\section{Discussion}

Acute interstitial pneumonia was found in a higher numeric proportion of heifers than would have been expected based on the proportion of heifers in the feedlot (75\%). During the ante-mortem phase of this study, $87 \%$ of the animals suspected of AIP were heifers $(n=27)$ and during the post-mortem phase $96 \%$ of the cattle with AIP confirmed on histology were heifers. This numeric finding agrees with previous studies that reported feedlot heifers were more prone to be affected by AIP than steers. In a study conducted in southern Alberta feedyards, all the animals suspect of AIP were heifers even though the heifer to steer ratio during the time of the study was 8:1 (Ayroud et al., 2000). Woolums et al. (2001) also reported that heifers died of AIP at higher ratios than steers.

In this study, AIP affected cattle from 24 to 131 DOF and at an average body weight of $505 \mathrm{~kg}$. Acute Interstitial Pneumonia has been reported in cattle as early as $45 \mathrm{~d}$ and to continue in cattle up to 15 to $45 \mathrm{~d}$ prior to expected slaughter date (Woolums et al., 2001; Stanford et al., 2006). In other studies, AIP was observed to be a prevalent cause of death in cattle that are nearing market weight (Jensen et al., 1976; Loneragan and Gould, 1999). In a nationwide survey evaluating the association between management practices and the risk of AIP, feedlot managers reported that about $80 \%$ of all the AIP deaths were in cattle that had been on feed for 60 days or more and averaged $24 \mathrm{~d}$ before expected slaughter date (Ayroud et al., 2000).

Acute Interstitial Pneumonia has been reported to affect cattle more commonly during hot and dry summers (Ayroud et al., 2000; Woolums et al., 2005a) or during the fall season (Hammond et al., 1979). It is possible that heat stress contributes to the incidence of 
AIP. This study was conducted for about $60 \mathrm{~d}$ during the months of June, July and August. Cattle suspected of AIP were shown to have $(p<0.0001)$ greater rectal temperature values $\left(40.6 \pm 0.16^{\circ} \mathrm{C}\right)$ than the control animals $\left(39.7 \pm 0.16^{\circ} \mathrm{C}\right)$. It is not possible to determine if the increased rectal temperature was an immune response, accumulated heat load, or caused by other factors.

At necropsy, animals suspected of AIP presented pulmonary characteristics such as enlarged lungs, dark red color, rubbery texture and interstitial edema and intralobular emphysema. These lesions were often diffusely distributed throughout the lung lobes. These observations were similar to gross lesions reported in previous studies (Curtis et al., 1979; Woolums et al., 2005b; Doster, 2010). Histological evaluation of lung samples showed that bronchiolitis lesions were present in more than $90 \%$ of the cattle affected with AIP. About $75 \%(34 / 45)$ of the cattle with AIP also had bronchopneumonia lesions. The percentage of AIP cattle with bronchopneumonia was in agreement with previous reports. In a study of feedlot-associated AIP, $97 \%$ of the cattle affected with AIP $(\mathrm{n}=149)$ also presented evidence of bronchopneumonia $(\mathrm{n}=144)$ (Hjerpe, 1983). In another study, $75 \%$ of the cattle with AIP $(n=$ 28) also became affected with bronchopneumonia $(\mathrm{n}=$ 21) (Sorden et al., 2000).

Ante-mortem serum amylase, lipase and rumen $\mathrm{pH}$ did not differ between cattle diagnosed with AIP and those without AIP. Hydrogen sulfide has been shown to cause lung lesions in rats (Lopez et al., 1987; Prior et al., 1988). If rumen $\mathrm{H}_{2} \mathrm{~S}$ concentrations contribute to AIP, it would be reasonable to expect $\mathrm{H}_{2} \mathrm{~S}$ to be higher in cattle affected by AIP than control animals. However in this experiment, AIP animals had numerically lower concentrations of $\mathrm{H}_{2} \mathrm{~S}$ than the control animals. The postmortem $\mathrm{H}_{2} \mathrm{~S}$ levels were about 8 times greater than the ante-mortem levels. Post-mortem rumen $\mathrm{pH}$ values were numerically greater in the 60 AIP animals than 11 control animals (6.3 Vs. 5.7, respectively), which agrees with previous reports (Miles et al., 1998).

Feed factors such as readily available L-tryptophan and disturbances in feed intake patterns have been suggested as factors that contribute to increased AIP incidence. Feedlot diets typically do not contain high levels of highly available protein and the amino acid Ltryptophan that can be present in lush forages. However, increased levels of breakdown products of L-tryptophan have been found in the lungs of feedlot cattle with AIP (Loneragan et al., 2001a). In this study, there were no differences in feed intake patterns between pens that experienced a case of AIP and those that did not.

\section{Conclusion}

This study generally confirms the observations that AIP tends to occur in heifers, late in the feeding period and tends to be associated with bronchiolitis and bronchopneumonia. Cattle suspected of AIP had greater rectal temperature values $\left(40.6 \pm 0.16^{\circ} \mathrm{C}\right)$ than animals classified as controls $\left(39.7 \pm 0.16^{\circ} \mathrm{C}\right)$. The lack of differences in rumen measures and the feed intake data between AIP and control cattle suggest that feed intake pattern and rumen fermentation may not impact AIP in feedlot cattle. Future AIP research topics include the complications of heat stress, dusty conditions and water availability. Also, there are currently few effective treatments.

\section{Acknowledgement}

The authors acknowledge a commercial feedyard in southwest Kansas for their cooperation in this study.

\section{Funding Information}

This study was funded by the Beef Cattle Institute, Kansas State University.

\section{Author's Contributions}

Jose E. Valles: Performed the animal study and collected samples, performed data analysis and prepared the initial manuscript.

Daniel U. Thomson, Michael D. Apley and Chris D. Reinhardt: Conceptualized the study and were responsible for experimental design and participated in preparation of the publication.

Steven J. Bartle: Participated in the data analysis and interpretation and drafted the final manuscript. All authors approved the final version of the manuscript for publication.

\section{Ethics}

The authors declare that they have no competing interests.

\section{References}

Amosson, S.H., B. Guerrero and L.K. Almas, 2006. Economic analysis of solid-set sprinklers to control dust in feedlots. Proceedings of the 38th Southern Agricultural Economics Association Annual Meeting, Feb. 5-8, Orlando, pp: 1-20.

Ayroud, M., J.D. Popp, M.A. VanderKop, G.S. Yost and D.M. Haines et al., 2000. Characterization of acute interstitial pneumonia in cattle in Southern Alberta feedyards. Can. Vet. J., 41: 547-554. PMID: 10907577

Blood, D.C., 1962. A typical interstitial pneumonia of cattle. Can. Vet. J., 3: 40-47.

Curtis, R.A., R.G. Thomson and W.C.D. Sandals, 1979. Atypical interstitial pneumonia in cattle. Can. Vet. J., 20: 141-142. 
Doster, A.R., 2010. Bovine atypical interstitial pneumonia. Vet. Clin. North Am. Food Anim. Pract., 26: 395-407.

DOI: $10.1016 /$ j.cvfa.2010.03.002

Hammond, A.C., B.J. Bradley, M.T. Yokoyama, J.R. Carlson and E.O. Dickinson, 1979. 3-methylindole and naturally occurring acute bovine pulmonary edema and emphysema. Am. J. Vet. Res., 40: 1398-1401. PMID: 525860

Hjerpe, C.A., 1983. Clinical management of respiratory disease in feedlot cattle. Vet. Clin. North Am. Large Anim. Pract., 5: 119-142. PMID: 6351409

Jensen, R., R.E. Pierson, P.M. Braddy, D.A. Saari and L.H. Lauerman et al., 1976. Atypical interstitial pneumonia in yearling feedlot cattle. J. Am. Vet. Med. Assoc., 169: 507-510. PMID: 956028

Kleen, J.L., G.A. Hooijer, J. Rehage and J.P. Noordhuizen, 2004. Rumenocentesis (rumen puncture): A viable instrument in herd health diagnosis. Deutsche Tierärztliche Wochenschrift, 111: 458-462. PMID: 15648614

Loneragan, G. and D. Gould, 1999. Acute interstitial pneumonia in U.S. feedlots. Proc Acad Vet. Consultants Winter Meeting, pp: 1-6.

Loneragan, G.H., D.H. Gould, G.L. Mason, F.B. Garry and G.S. Yost et al., 2001a. Association of 3methyleneindolenine, a toxic metabolite of 3methylindole, with acute interstitial pneumonia in feedlot cattle. Am. J. Vet. Res., 62: 1525-1530. DOI: 10.2460/ajvr.2001.62.1525

Loneragan, G.H., D.H. Gould, G.L. Mason, F.B. Garry and G.S. Yost et al., 2001b. Involvement of microbial respiratory pathogens in acute interstitial pneumonia in feedlot cattle. Am. J. Vet. Res., 62: 1519-1524. DOI: 10.2460/ajvr.2001.62.1519

Lopez, A., M. Prior, S. Yong, M. Albassam and L.E. Lillie, 1987. Biochemical and cytologic alterations in the respiratory tract of rats exposed for 4 hours to hydrogen sulfide. Fundamental Applied Toxicol., 9: 753-762. DOI: 10.1016/0272-0590(87)90182-5

Miles, D.G., B.W. Hoffman, K.C. Rogers and J.E. Sears, 1998. Diagnosis of digestive deaths. J. Anim. Sci., 76: 320-322. PMID: 9464914

NAHMS, 2000a. Part II: Baseline reference of feedlot health and health management. USDA, APHIS, National Animal Health Monitoring System.
NAHMS, 2000b. Part III: Health management and biosecurity in the U.S. Feedlots. USDA, APHIS, National Animal Health Monitoring System.

Prior, M.G. A.K. Sharma, S. Yong and A. Lopez, 1988. Concentration-time interactions in hydrogen sulphide toxicity in rats. Can. J. Vet. Res., 52: 375-379. PMID: 3167719

Sorden, S.D., R.W. Kerr and E.D. Janzen, 2000. Interstitial pneumonia in feedlot cattle: Concurrent lesions and lack of immunohistochemical evidence for bovine respiratory syncytial virus infection. J. Vet. Diagnostic Invest., 12: 510-517. DOI: $10.1177 / 104063870001200604$

Stanford, K., T.A. McAllister, M. Ayroud, T.M. Bray and G.S. Yost, 2006. Effect of dietary melengestrol acetate on the incidence of acute interstitial pneumonia in feedlot heifers. Can. J. Vet. Res., 70: 218-225. PMID: 16850945

Woolums, A.R., G.H. Loneragan, L.L. Hawkins and S.H. Williams, 2005a. A survey of the relationship between management practices and risk of acute interstitial pneumonia at US feedlots. Bov. Pract., 39: 125-133.

Woolums, A.R., G.H. Loneragan, S.M. Hawkins and S.H. Williams, 2005b. Baseline management pracitices and animal health data reported by the US feedlots to a survey regarding acute interstitial pneumonia. Bov. Pract., 39: 116-124.

Woolums, A.R., G.L. Mason, G.L. Hawkins, C.C. Brown and S.M. Williams et al., 2004. Microbiologic findings in feedlot cattle with acute interstitial pneumonia. Am. J. Vet. Res., 65: 1525-1532. DOI: 10.2460/ajvr.2004.65.1525

Woolums, A.R., S.M. McAllister, G.H. Loneragan and D.H. Gould, 2001. Etiology of acute interstial pneumonia in feedlot cattle: Noninfectious causes. Comp. Continuing Ed., 23: 86-93.

Zhou, M.T., C.S. Chen, B.C., Q.Y. Zhang and R. Andersson, 2010. Acute lung injury and ARDS in acute pancreatitis: Mechanisms and potential intervention. World J. Gastroenterol., 16: 2094-2099. DOI: 10.3748/wjg.v16.i17.2094 